\title{
Extending Support for English Language Learners: A University Outreach Program
}

\author{
Maureen Snow Andrade \\ Utah Valley University \\ U. S. A.
}

As universities in English-speaking countries recruit and enroll international students, a variety of forms of support are typically offered on and off campus to help students make a successful transition. The most common challenges for nonnative English-speaking international students are linguistic and cultural. In spite of meeting English proficiency score requirements for admission, students report struggling with the demands of academic English. This article describes a model for an on-site English language program to help students improve their levels of English proficiency prior to their arrival. Program effectiveness was assessed through pre- and post-test measures of students' English language skills, interviews with stakeholders, and observations. Students' gains in proficiency were moderate due to the limited amount of time they had available for course attendance and study, but gains in affective factors were strong. Challenges in the implementation of the program and how they were resolved are described.

\author{
Approaches to Support \\ The Outreach Program \\ Program Evaluation \\ Program Outcomes \\ Challenges and Opportunities \\ Conclusion \\ References
}

International students have a significant presence in higher education institutions in English-speaking counties. Twenty percent of all post-secondary international students choose the United States as their destination, followed by the United Kingdom with $13 \%$ of the market share (Institute for International Education [IIE], 2008c). International students in U.S. institutions comprise over $3 \%$ of the total enrollment and $12 \%$ of graduate enrollments (Bhandari \& Chow, 2007). In other countries, they account for an even larger percentage. Twentyone percent of Australian higher education enrollments are international students (IIE, 2008a).

Institutions of higher education commonly acknowledge the benefits of admitting international students. These include revenue generation, institutional support, and intercultural learning (NAFSA, 2006). The U.S. economy benefits from approximately $\$ 15$ million annually from international students and their 
dependents (IIE, 2008b). International graduate students serve as teaching and research assistants, often in scientific fields with low domestic student enrollments (Jacobs, 2005; Trice, 2003). Campus events involving international students build intercultural sensitivity (Deardorff, 2009), and professors note that international students contribute diverse perspectives in their classrooms (Andrade, 2010; Coleman, 1997).

The majority of colleges and universities require evidence of English proficiency for admission, generally measured by a standardized proficiency test such as the TOEFL; however, students may still be unprepared for differences in dialect, speed of discourse, academic language, expectations for accuracy in written work, oral and written discourse patterns, and large amounts of required reading (Andrade, 2009; Cheng, Myles, \& Curtis, 2004; Holmes, 2004; Huang, 2004; Schutz \& Richards, 2003). Additionally, cultural differences potentially affect adjustment and may contribute to homesickness, isolation, and clustering among co-cultural peers (Hechanova-Alampay, Beehr, Christiansen, \& Van Horn, 2002; Lacina, 2002; Meyer, 2001). These findings point to the need for programming that supports the linguistics, academic, and cultural transition of international students.

Universities and colleges invest considerable amounts of time and resources recruiting international students and developing strategies and support programs on their behalf both prior to arrival and on campus. These programs commonly focus on practical information related to immigration requirements, cultural adjustment, and settling in (Andrade \& Evans, 2009). Seldom do prearrival programs focus on English language support or understanding of academic expectations, nor do they involve students in actual coursework to prepare them for a successful linguistic, academic, and cultural transition.

This article describes an innovative program developed by a university with a large enrollment of international students. The purpose of the program is to strengthen students' English language skills and increase their understanding of the U.S. university system and culture prior to their admission and arrival on campus. In this article, I explore factors related to the implementation, evaluation, and modification of the program in order to provide insights into the viability of this form of international student support. First, I review common approaches to international student support. Then I provide a discussion of outcomes of the onsite program.

\section{Approaches to Support}

English language support for nonnative English speakers (NNES) takes a variety of forms in higher education. Many institutions in the United States offer intensive English programs (IEP) that are typically non-credit and often housed in an extended education unit. International students whose English proficiency is below that needed for admission may initially study in an IEP. Some campuses 
offer a limited array of credit-bearing courses, such as advanced level reading and writing, which may be required or elective. Depending on institutional approach to language issues, English language testing may occur on campus in addition to that required for admission.

Increasingly, a content-based approach to language support is being adopted. This involves concurrent enrollment in a content course (e.g., history, biology) along with an English as a Second Language (ESL) course (Andrade, 2007). The ESL course uses the content course materials as a basis for strengthening students' listening, vocabulary, reading, writing, and discussion skills and helps them succeed in the content course. Variations of this approach, such as learning communities in which ESL students are co-enrolled in language and multiple content courses, have been highly successful (Babbitt \& Weiss, 2009; Mlynarczyk \& Babbitt, 2002).

Other kinds of creative programs offer support to students who may have met admission requirements but struggle with the demands of coursework in terms of English language skills. These include CD-ROM based support (Wu, Griffiths, Wisker, Waller, \& Illes, 2001), supplemental courses (Beasley \& Pearson, 1999), and study buddy programs (Mendelsohn, 2002; Ronesi, 2001). The latter involve partnering native English speakers and nonnative English speakers enrolled in the same courses. Additionally, courses, tutorials, and support groups focused on thesis and dissertation writing are often available to ESL graduate students (Sundstrom, 2009).

English language development has also been identified as a need for students enrolled in courses offered away from the main campus in international locations, a common practice for Australian universities. Instructors of these courses report that students need more preparation in English and lack understanding of academic expectations (Hussin, 2007). They indicate that the ideal means of providing English language support is face-to-face and advocate for the presence of trained ESL teachers on site, although online support, CDs, books, and videos are more typical forms of academic support.

Indeed, with the growing sophistication of educational technology, distance education programs are becoming a feasible means of addressing English language learning needs. Although courses focused on teaching language from a distance have been slower to develop than courses in other disciplines (Hurd, 2006), this approach is becoming more viable. One of the challenges with this method, however, is providing the interactivity needed for language acquisition in terms of input and output (e.g., see Krashen, 1982, 1985; Swain, 1995).

Another challenge that must be addressed related to English language support courses is that students who have been admitted to a university may not wish to spend additional time and money focusing on their English skills, instead preferring to begin their course of study immediately (Wu et al., 2001). Although required on-campus testing and courses offer one way to address this need, this may result in negative student reactions. It may also be difficult to encourage 
students to take optional courses, as they would rather spend the time on their course of study even though improved English skills would help them be more effective and efficient (Andrade, 2008a).

English language coursework typically goes beyond the study of English to include practical information about the higher education system including credit hours, registration, course prerequisites, and graduation requirements. Common classroom practices and expectations for active learning, note-taking, homework, exams, professors' office hours, and class attendance may also be addressed, along with information related to cultural adjustment. The latter typically focuses on the benefits of interaction with students outside one's own culture, ethnocentrism, common customs and values, local community practicalities, and host country holidays, celebrations, history, and government.

This information may be provided informally by caring teachers who understand the needs of international students as they embark on their studies, or it may be integrated into English language coursework (e.g., see Kimoto, 2009). Another approach is to offer courses specifically designated for this purpose, such as a first year seminar for international students (Andrade, 2006). Possibilities also include pairing international and domestic students for the purpose of social interaction and increased cultural understanding (e.g., see Abe, Talbot, \& Geelhoed, 1998; Deardorff, 2009; Hallett; 2009; Jacob \& Greggo, 2001; Shigaki \& Smith, 1997). Orientation programming, sometimes extending over the course of a semester or longer, is another means of addressing social and cultural transition needs (e.g., see Housely, 2009; Rhodes, Cox, \& Ebner, 2009; Silver, 2009) while community programs help students and community members connect for the purpose of increased cultural understanding (e.g., see Audas, 2009; Fluck, 2009).

\section{The Outreach Program}

As established in the previous section, possibilities for international student support are considerable. Institutions must identify those that are context-appropriate in terms of their mission, student needs, available resources, and effectiveness. Support should be holistic, addressing linguistic, academic, and cultural transition needs. This section describes how a private, religiouslyaffiliated, undergraduate university in the United States established an outreach program focused on the transition needs of a specific population of international students prior to their admission and enrollment.

International students at the institution originate predominantly from Asia and the Pacific Islands and constitute almost half of the university's total enrollment of 2,400. Most are nonnative English speakers (NNES) and have met the admission requirement of 61 on the Internet-based (iBT) TOEFL (Test of English as a Foreign Language) or its equivalent. Many of these students are from developing nations and lack the opportunity to pursue higher education due 
to selective educational systems in their countries or financial limitations. As such, the university financially sponsors many of them through a work-study program.

Because this financial sponsorship is significant and students need time to strengthen their English language skills once at the university, the institution has a vested interest in helping them develop the English language skills necessary for academic success prior to their arrival. While English language development is possible in many countries due to English use in the educational system and the availability of private English language schools, these opportunities can be limited in some nations, and the cost of private study may present a barrier. Furthermore, to support successful adjustment and encourage persistence, cultural transition needs must be considered.

To address these factors, the university launched an outreach program with the idea that if it were viable, it could be extended to other sites. The country of Tahiti was selected for the program because potential students there lacked opportunities to learn English and stakeholders expressed support. The university had a particular interest in this nation and others in the Pacific and Asia, due to the institution's location and mission to provide educational opportunities for individuals from this region of the world.

\section{Curriculum and Instruction}

The program, implemented in 2001, utilized the existing infrastructure of a local religious organization in terms of a teaching site, equipment, computer support, and student recruitment. (The university is affiliated with this same religious organization.) As the purpose of the program was to increase students' English skills and prepare them for the cultural and educational context of a U.S. university prior to admission, the primary criterion for participation was the intention of applying for admission. Classes were offered in the evenings and on Saturdays, as many potential students were either in their final year of high school, a university preparatory year equivalent to the first year of college in the United States, or working.

Initially, approximately 30 students enrolled and received about three formal hours of English language instruction per week. They were encouraged to spend additional time with self-instruction computer modules. Most were between the ages of 18 and 24. English levels varied, with a few students exhibiting no functional ability in the language and a few others at the advanced levels. Most were at a high beginning or low intermediate level of proficiency. In addition to formal class hours, the director and teachers sponsored evening discussions and social activities. These featured cultural experiences such as American food, games, celebrations, or pastimes.

A native-English speaking volunteer couple initially directed and taught in the program. Volunteers can make significant contributions in the field of TESOL 
(Snow, 2006), particularly if they receive training and work closely with professionals. Both of these factors were true in this case. The couple received training at the university and was supervised by the university's ESL program director. One of the couple was fluent in French, an official language of Tahiti. Both had teaching backgrounds. In order to increase the level of expertise and program stability, subsequent iterations of the model involved hiring a TESOLtrained director/teacher with volunteer teachers assisting. This director had graduated from the university and was thus familiar with its academic systems and student life. She served as a role model for students, as she had experienced the cultural and educational transition that they anticipated.

The curriculum involved the use of a computer software program consisting of six levels of English language instruction, predominantly focused on grammar, vocabulary, and pronunciation. The program included a placement test and allowed students to work independently at their own level. This was particularly helpful as enrollments in the program were small at times and students had differing levels of proficiency. Classroom instruction reflected the on-campus curriculum, and communicative activities provided opportunities for interaction. Students were often paired or divided into small groups so that they interacted with peers possessing a similar command of the language, or to allow higher level students to support those at a lower level. This also helped students become accustomed to the U.S. classroom practice of pair and group work. Graded readers provided additional language input and motivation.

To augment language instruction, students participated in cultural activities related to American holidays (e.g., Halloween, Thanksgiving, Mother's/Father's Day), read news about current issues in the United States (e.g., elections, the economy, popular culture), and learned about daily life through cooking demonstrations, movies, music, stories, and realia. The instructors also provided students and their parents with information and support related to university admission paper work, immigration requirements, courses of study, campus life, financial preparation, living arrangements, and other practicalities. They modeled classroom customs and culture to familiarize students with academic expectations. The outreach center itself featured pictures of the campus and student activities to help students visualize the environment that they would encounter. Students also connected with the campus culture through campus news items over the Internet.

\section{Program Evaluation}

To evaluate the program's success, I gathered information from a variety of sources. The data focused on the following questions: 1) How effective is the program in helping students increase their levels of English? 2) How effective is the program in helping students increase their understanding of the U.S. educational system and culture? 3) What additional benefits might the program have (e.g., creating a positive image of the university, enabling employment 
opportunities, and improving self-confidence)? Test scores, observations, interview data, and information from interactions with stakeholders were analyzed to answer these questions and determine the usefulness of the model.

Related to the effectiveness of the outreach model in helping students improve their English skills, a pre/post-test design was adopted. As director of the university's ESL program, I traveled to the on-site program to administer a series of English language assessments to those enrolled in the program as they began their studies in the latter part of 2001. I returned eight months later to administer post-tests. On both visits, I also collected information about the program's benefits through qualitative measures.

English language assessment measures included the Secondary Level English Proficiency (SLEP) test, published by Educational Testing Services (ETS) and used in the university's on campus ESL program. The first part of the test measures listening skills and the second part measures reading, grammar, and vocabulary. Each part has 75 multiple choice questions. Standardized proficiency English tests of this type measure passive knowledge of the language.

To assess communicative uses of English, I administered a 30-minute writing sample, which was scored by instructors in the on-campus ESL program according to a standardized rubric. Scores on the rubric had been benchmarked to various proficiency levels in the program. I also conducted an oral interview using Oral Proficiency Interview guidelines (American Council on the Teaching of Foreign Languages, 2009). This test ascertains an individual's functional ability in a foreign language through a face-to-face interview with a certified tester. The individual's performance is compared to specific criteria for 10 different proficiency levels—novice low/mid/high, intermediate low/mid/high, advanced low/mid/high, and superior. In addition, students completed a short, demographic survey (translated into the native language) regarding their English background and the degree to which they used and/or studied English outside of class.

I collected additional information over the course of two week-long visits through class observations, discussions with the volunteer teachers, and a review of student records, teaching resources, and lesson plans. I interacted with the students as they worked on the computer program and participated in classroom activities and social events. I met with parents and local religious leaders. These sources of information provided insights into the students' cultural learning, educational adjustment, and related affective factors. Based on these sources, I identified tentative themes that represented the experiences of the participants (Marshall \& Rossman, 1999). I shared these with the teachers to ensure an accurate representation of the information; thus, the teachers served as auditors of the analysis (Lincoln \& Guba, 1985). Multiple sources of data and obtaining the observations of multiple parties ensured triangulation and accuracy (Glesne, 1999). 


\section{Program Outcomes}

I analyzed the information collected to determine the effectiveness of the outreach program. As mentioned, English skills were measured directly using a number of different instruments. Additional information related to program outcomes emerged as the result of observations, discussions, document review, and stakeholder interactions.

\section{English Skills}

Regarding the effectiveness of program participation in helping students increase their levels of English so that they would spend less time studying English at the university, proficiency increases (as measured by test scores) were modest although some students made gains in some areas. The total number of students who participated in the pre- and post-tests was 18 due to attrition or the students' lack of availability at the time of testing. Half of the students demonstrated enough proficiency to advance to a higher level of instruction in listening, while $27 \%$ demonstrated advancement in speaking and reading, and $22 \%$ in writing. Six students (33\%) demonstrated scores high enough to advance in more than one area. The greatest gains were made in listening, perhaps due to greater exposure and input. It is possible to attribute these gains to the program. However, as scores on standardized proficiency tests represent a range of proficiency, small increases or decreases in scores may not necessarily indicate changes in linguistic proficiency.

During the 8-month period, four students were accepted to the university. An additional three were accepted at a later date. These students had scores in the range required for admission (either slightly higher or slightly lower) prior to enrolling in the program. In spite of already having admissible or close to admissible scores, these students likely still benefited from the practice provided by the computer software, instructor feedback, and interaction in English. However, the fact that some students discontinued their involvement with the program after they were admitted worked against the goal of attaining a level of English that would allow them to test out of on-campus English language courses.

The survey findings indicated that most students used little English in daily life and their study of the language predominantly occurred in their class sessions. This was true for those who made gains as well as for those who did not, although students who had the highest initial levels of proficiency had had greater opportunities for English learning from an English-speaking parent, employment involving English usage, or extended visits to English-speaking countries. As language acquisition thrives on opportunities for input and output (e.g., see Krashen, 1982, 1985; Long, 1996; Swain, 1995), the lack of 
opportunities to hear and use English in a variety of contexts and with a variety of people was a disadvantage.

\section{Affective Factors and Educational Aspirations}

Non-English language benefits from the program were particularly strong and were the most significant outcomes of the program. Based on discussions with the instructors and students and from observations, stakeholders appreciated the program. The students had formed close relationships with the teachers and benefited from their encouragement, which influenced them beyond their English language studies. The positive relationship between the students and their instructors lowered their affective filters and helped them feel comfortable in the learning environment. Students had gained confidence in their ability to use English and had a greater sense of direction in terms of future educational and career plans. Most of the students intended to apply to the university, but also recognized that English skills would open other opportunities such as working in the tourist industry in Tahiti.

The teachers served as role models, particularly in the case of the local nonnative English-speaking teacher and also as advisors/career counselors. The native-English-speaking volunteer teachers from abroad represented the world outside the island and were able to help students recognize their potential and the benefits of an education. They constantly encouraged students to attend classes by making personal contact with them and reminding them of deadlines. The volunteer teacher who spoke French was a particular favorite, although this ability was sometimes a disadvantage as he loved to speak French rather than English. Overall, however, this skill helped the students feel at ease in the teaching-learning situation. These interactions and positive learning experiences increased the students' desires to pursue an education and created positive impressions of American people and culture.

\section{Marketing and Public Relations}

In addition, the teachers from abroad played an active role in promoting the university and providing information to parents and students about the admissions process and what to expect at the institution. Admissions officers on campus reported that the program created more interest in applying to the university than had occurred for several years. They accounted for this by the presence of representatives on-site who encouraged individuals to apply for admission and assisted with applications. Students and parents appreciated that the university had provided students with the opportunity to study English and prepare for a successful academic and cultural transition. Communication between the institution and prospective students was much improved by having a specific location to which individuals could go not only for guidance and 
information, but for coursework and to access English language learning materials.

\section{U.S. Educational System and Culture}

Through coursework, class sessions, and related activities, students became acquainted with expectations for classroom participation. As mentioned, students' confidence using English increased because they felt they were in a safe environment. The fact that one of the teachers had learned the students' native language fluently provided them with a source of motivation for learning English. They recognized that this individual had overcome challenges to acquire a second language and that they could do the same. The bond between the teachers (from both abroad and Tahiti) and the students was created through group activities, invitations to the teachers' homes, cultural celebrations, sharing of cultural practices, and lesson materials that reinforced language learning and broadened students' perspectives about English-speaking countries, particularly the United States.

As the students and their parents worked with the teachers to navigate the admissions process, they learned much about institutional features such as courses of study, registration, graduation requirements, credit hours, and so forth. Additionally, the director/teacher who had graduated from the university was able to share her academic and social experiences with the students and help them compare the educational system and culture in their country to what they would encounter in the United States.

\section{Challenges and Opportunities}

The purpose of evaluation is to inform curriculum and related program structures with the goal of improving student learning and success. This was also the purpose for evaluating the outreach program - to determine its effectiveness and identify needed modifications. Some key challenges of the program became apparent through the evaluation process, which are here reframed as opportunities in order to strengthen student success. The evaluation and resulting findings provided important information that was utilized to improve subsequent iterations of the on-site program. The majority of these are related to English language learning, as that was the least successful aspect of the program. Program features involving orientation to academic expectations and cultural learning were largely positive, as was public relations. Modifications have occurred gradually with each being reviewed on an on-going basis through onsite visits and communications with the program coordinator. 


\section{Commitment}

Cultural barriers to success must be considered when programs based in one culture are implemented in another. As was evident from the attrition rate between the pre- and post-English language testing, students varied in their levels of commitment. The demands of the education system and values related to home, family, and religion were at times unsupportive of continued program participation. The university preparatory year was rigorous, and family needs and religious involvements were a priority. Similarly, the transportation system was not extensive or reliable, contributing to attendance problems.

Data collection and teacher records indicated that those who had stopped attending classes had done so for the reasons stated above, as well as not passing the university preparatory year (required for admission), lack of finances to attend the university, not being admitted, becoming less active in the sponsoring religious organization, pursuing career opportunities, employment demands, and lack of immediate plans to attend the university. In addition, the program was not required for admission and was free of charge, which tended to lessen commitment to attendance.

To address these factors to the extent possible, during subsequent revisions of the program scheduling conflicts were addressed so that students could work or attend to family responsibilities and still participate. The flexibility of the self-paced computer software was an asset in this regard, and computer lab hours were arranged to accommodate students. Along with this, the teachers provided students with online learning opportunities for those who had access to computers and the Internet. Printed materials were also made more available for home use. Improving access helped to strengthen commitment. Additionally, charging a tuition fee suitable to the economy helped strengthen commitment and offset program costs.

\section{Curriculum Focus}

Although a key objective of the program was to help students improve their English skills so that they would be more prepared for their studies and spend less time in ESL courses, the focus turned to test preparation in order to achieve the needed score for admission. This perspective was partly due to familiarity with an educational system in which future opportunities were largely determined by test scores. The result was a short-sighted approach, causing some students to stop attending once they had been admitted to the university even though they would still need to spend a considerable amount of time in ESL courses on campus.

Initially, policies were not in place to encourage or require students who had met admission standards or had already been admitted to continue their 
studies. (Even so, the program helped those who possibly would not otherwise have been accepted.) To demonstrate its commitment to the program and to strengthen student persistence, the university began to give preference for admission to students who were enrolled in the program, actively working to improve their English, were recommended by the on-site teachers, and had made gains in skill levels. Thus, cultural perspectives were addressed by clarifying that test scores alone were not valued in the admission process.

\section{Language Acquisition}

While the program was open to those wanting to improve their skills for admission purposes, some students did not understand the amount of time and commitment needed to reach this goal. This was evident in the sporadic attendance and the practice of discontinuing attendance when admitted to the university. In some cases, students with minimal English skills enrolled with unrealistic expectations of the progress they could make and what would be required to make the significant gains in English needed for admission.

Modifications to the program, based on this finding, resulted in limiting enrollment to students who were reasonably close to the score needed for admission and to those who had already achieved this score. This change recognized that, realistically, large gains in proficiency are not likely to occur with only moderate language study and limited time on task. Expectations of what can be accomplished given the non-English speaking learning environment and amount of time for English study were thus more clearly established for students and parents. In this way, cultural and individual views about language learning were addressed.

Students with lower levels of proficiency were enrolled when space was available but with a clear understanding of what it would take to achieve the level of proficiency for admission. The computer software program and other materials were made available to them, however, so that motivated students would have the opportunity to advance. Tracking of this modification indicated that those who spent significant amounts of time with the software were able to make linguistic gains.

\section{English Language Input}

Feedback regarding the computer software program was positive. Students thoroughly enjoyed it, and the instructors indicated that it was userfriendly. The physical facilities and other resources, including computer support, were adequate, although additional teaching resources to supplement the computer program such as graded readers, activity books, and teacher reference materials were needed as the available resources were limited in number and 
variety. To strengthen opportunities for language input, program changes involved identifying English language learning resources on the Internet and increasing the collection of reading materials to provide variety and further support for English language development.

Another feature that has been implemented to extend opportunities for input and output is distance learning opportunities for writing and speaking tutoring to expose students to other models of English and provide interaction beyond the on-site classroom. As the program has expanded to other locations, more online components and live tutorials from campus have been implemented. Native speakers within Tahiti, such as alumni of the university, are also utilized for conversation practice with students, and serve as language models, role models, and informants about the institution, thus extending what is provided by the course teachers. In this way, both linguistic and cultural learning opportunities are extended.

\section{Conclusion}

Through the outreach program, students gained some foundational knowledge in English. Several students were admitted to the university, although it cannot be claimed that this was solely due to the instruction they received in the outreach program. Given the restricted amount of time students were able to attend classes and the non-English speaking context, the minimal measureable gains achieved in proficiency are understandable. Based on the evaluation conducted, the program is not significantly decreasing the amount of time students need to spend studying English at the university unless students can devote more time to their study of English while in the program. However, the program is clearly supported by all those involved and is providing students with an encouraging learning atmosphere and a stronger English language foundation. Additionally, modifications to the program have had a positive impact in addressing initial challenges.

In considering the effectiveness and expectations of programs such as this, the costs and potential linguistic gains of providing ESL instruction on campus rather than through an outreach program in a non-English-speaking environment must be considered. Non-linguistic gains, such as recruitment and marketing, however, may be sufficiently positive to ameliorate limitations in linguistic gains and make programs such as these worthwhile. Students who become familiar with an institution through a quality English language program in their own countries are likely to choose that institution as their destination of study in the United States. This results in the financial and intercultural learning benefits for institutions that were outlined earlier. Intercultural learning does not typically occur without intervention in terms of training and programming on the part of the institution (e.g., see Andrade, 2008b, 2010), however. On-site programs may be a first step. 
Gains for students in terms of familiarity with U.S. higher education, linguistic confidence, and access to information about the host country and institution are also positive and were, in fact, the primary benefits of the program. These features, designed to aid students in their academic and cultural transition, are the focus of ongoing assessments regarding the degree to which the on-site program affects the transition process for those who enroll at the university. Student reports of their in-country introduction to U.S. university life, language learning, and academic expectations indicate a positive impact on subsequent campus experiences.

The university sponsoring this outreach program has distinct characteristics, namely the large population of international students and its mission to provide educational opportunities (and in many cases, financial sponsorship) to specific international student populations. Although the evaluation of the program involved relatively few students and only one country, the lessons learned have potential application to other institutions. The program offers a model for supporting students' transitional needs prior to their arrival at an institution. Program features could be adapted to fit a variety of student populations and institutional missions. Many universities have international initiatives for the purpose of recruitment, orientation, and course delivery. These could be augmented with English language and cultural learning opportunities.

Outreach programs designed to assist potential international students in the pre-arrival stage for purposes of recruitment, orientation, English language acquisition, and cultural learning can be very effective in helping students have a successful transition once on campus. The university that sponsored this program has been successful in implementing a number of variations of the model to fit different contexts and student needs. These variations were the result of findings and experiences with the on-site program in Tahiti. The adaptions were designed to be appropriate to the context in terms of available technology and physical and human resources. These programs include on-site intensive English language programs similar to the Tahiti model, online/CD-ROM based English language course offerings, and combination on-site/distance learning models. All of these programs have had student success as their primary objective and have focused on linguistic, academic, and cultural transition issues. The results have been students feeling more comfortable and aware as they arrive on campus to pursue their studies.

\section{References}

Abe, J., Talbot, D. M., \& Geelhoed, R. J. (1998). Effects of a peer program on international student adjustment. Journal of College Student Development, 39(6), 539-547.

American Council on the Teaching of Foreign Languages. (2009). ACTFL proficiency guidelines - speaking. Retrieved from http://www.actfl.org/i4al pages/index.cfm?pageid=3349 
Andrade, M. S. (2006). A first-year seminar for international students. Journal of the First-Year Experience \& Students in Transition, 18(1), 85-103.

Andrade, M. S. (2007). Addressing the linguistic needs of nonnative English speakers in the first year. Journal of the First-Year Experience \& Students in Transition, 19(2), 69-86.

Andrade, M. S. (2008a). International graduate students: Adjusting to study in the United States. In K. A. Tokuno (Ed.), Graduate students in transition: Assisting students through the first year (pp. 71-88). Columbia, SC: National Resource Center for the First Year Experience \& Students in Transition.

Andrade, M. S. (2008b). The international student experience: Challenge, adjustment, and intercultural opportunity. In J. Van Rij-Heyligers (Ed.), Intercultural communications across university settings - myths and realities (pp. 30-41). Auckland, New Zealand: Pearson Education.

Andrade, M. S. (2009). The international student picture. In M. S. Andrade \& N. W. Evans (Eds.), International students: Strengthening a critical resource (pp. 1-24). Washington, DC: ACE/Rowman Littlefield.

Andrade, M. S. (2010). Increasing accountability. Faculty perspectives on the English language competence of nonnative English speakers. Journal of Studies in International Education, 14(3), 221-239.

Andrade, M. S., \& Evans, N. W. (2009). International students: Strengthening a critical resource. Washington, DC: ACE/Rowman Littlefield.

Audas, M. (2009). OU Cousins program. In M. S. Andrade \& N. W. Evans (Eds.), International students: Strengthening a critical resource (pp. 183-188). Washington, DC: ACE/Rowman Littlefield.

Babbitt, M., \& Weiss, T. (2009). Learning community programs: In support of student success. In M. S. Andrade \& N. W. Evans (Eds.), International students: Strengthening a critical resource (pp. 152-156). Washington, DC: ACE/Rowman Littlefield.

Beasley, C. J., \& Pearson, C. A. L. (1999). Facilitating the learning of transitional students: Strategies for success for all students. Higher Education Research \& Development, 18(3), 303-321.

Bhandari, R., \& Chow, P. (2007). Open doors: Report on international educational exchange. New York: Institute of International Education.

Cheng, L., Myles, J., \& Curtis, A. (2004). Targeting language support for nonnative English-speaking graduate students at a Canadian university. TESL Canada Journal, 21(2), 50-71.

Coleman, S. (1997). International students in the classroom: A resource and an opportunity. International Education, 26, 52-61.

Deardorff, D. (2009). Connecting international and domestic students. In M. S. Andrade \& N. W. Evans (Eds.), International students: Strengthening a critical resource, (pp. 211-215). Washington, DC: ACE/Rowman Littlefield. 
Fluck, U. (2009). Social support for international students through a community friendship program. In M. S. Andrade \& N. W. Evans (Eds.), International students: Strengthening a critical resource (pp. 116-120). Washington, DC: ACE/Rowman Littlefield.

Glesne, C. (1999). Becoming qualitative researchers: An introduction. (2nd ed.). New York: Longman.

Hallett, P. J. (2009). University of Utah's ambassador program. In M. S. Andrade \& N. W. Evans (Eds.), International students: Strengthening a critical resource (pp. 189-193). Washington, DC: ACE/Rowman Littlefield.

Hechanova-Alampay, R., Beehr, T. A., Christiansen, N. D., \& Van Horn, R. K. (2002). Adjustment and strain among domestic and international student sojourners. School Psychology International, 23(4), 458-474.

Holmes, P. (2004). Negotiating differences in learning and intercultural communication: Ethnic Chinese students in a New Zealand university. Business Communication Quarterly, 67(3), 294-307.

Housely, H. (2009). Creating connections. In M. S. Andrade \& N. W. Evans (Eds.), International students: Strengthening a critical resource (pp. 111115). Washington, DC: ACE/Rowman Littlefield.

Huang, J. (2004). Voices from Chinese students: Professors' use of English affects academic listening. College Student Journal, 38(2), 212-223.

Hurd, S. (2006). Towards a better understanding of the dynamic role of the distance language learning: Learner perceptions of personality, motivation, roles, and approaches. Distance Education, 27(3), 303-329.

Hussin, V. (2007). Supporting off-shore students: A preliminary study. Innovation and Teaching International, 44(4), 363-376.

Institute of International Education (IIE). (2008a). Atlas of student mobility. Global destinations. Retrieved from http://www. atlas.iienetwork.org/?p=48027

Institute of International Education (IIE). (2008b). Economic impact on states from international students. Retrieved from http://opendoors.iienetwork.org/ page/131554l

Institute of International Education (IIE). (2008c). Open doors 2008 fast facts. International students in the U.S. Retrieved from http://www.opendoors.iienetwork.org/file depot/0-10000000/010000/3390/folder/68485/Open+Doors+Fast+Facts+2008.pdf

Jacobs, B. (2005). The tangible contributions of international graduate students: An alternative approach and some evidence from the University of Rochester. Communicator, 38(4), 1-3.

Jacob, E. J., \& Greggo, J. W. (2001). Using counselor training and collaborative programming strategies in working with international students. Journal of Multicultural Counseling and Development, 29(1), 73-88. 
Kimoto, L. (2009). The English language instructor: A bridge to support services on campus. In M. S. Andrade \& N. W. Evans (Eds.), International students: Strengthening a critical resource (pp. 116-120). Washington, DC: ACE/Rowman Littlefield.

Krashen, S. (1982). Principles and practice in second language acquisition. New York: Prentice Hall.

Krashen, S. (1985). The input hypothesis: Issues and implications. London: Longman.

Lacina, J. G. (2002). Preparing international students for a successful social experience in higher education. New Directions for Higher Education, 117, 21-27.

Lincoln, Y. S., \& Guba, E. G. (1985). Naturalistic inquiry. Beverly Hills, CA: Sage.

Long, M. (1996). The role of the linguistic environment in second language acquisition. In W. Ritchie, \& T. Bhatia (Eds.), Handbook of second language acquisitions (pp. 413-468). San Diego, CA: Academic Press.

Marshall, C., \& Rossman, G. B. (1999). Designing qualitative research (3rd ed.). Thousand Oaks, CA: Sage.

Mendelsohn, D. (2002). The lecture buddy project: An experiment in EAP listening comprehension. TESL Canada Journal, 20(1), 64-73.

Meyer, J. D. (2001). A conceptual framework for comprehensive international student orientation programs. International Education, 31(1), 56-78.

Mlynarczyk, R. W., \& Babbitt, M. (2002). The power of academic learning communities. Journal of Basic Writing, 21(1), 71-89.

NAFSA: Association of International Educators. (2006, March). An international education policy for U.S. leadership, competitiveness, and security. Retrieved from http://www.nafsa.org/public policy.sec/united states international/toward an international/

Rhodes, G., Cox, L., \& Ebner, J. (2009). Orientation and re-entry programming for international students: The PLUS project. In M. S. Andrade \& N. W. Evans (Eds.), International students: Strengthening a critical resource (pp. 127-130). Washington, D.C: ACE/Rowman Littlefield.

Ronesi, L. (2001). Training undergraduates to support ESL classmates: The English language fellows program. TESOL Journal, 10(2, 3), 23-27.

Schutz, A., \& Richards, M. (2003). International students' experience of graduate study in Canada. Journal of the International Society for Teacher Education, 7(1), 10-23.

Silver, T. J. (2009). Foundations of success for international students: An extended orientation class. In M. S. Andrade \& N. W. Evans (Eds.), International students: Strengthening a critical resource (pp. 121-126). Washington, DC: ACE/Rowman Littlefield. 
Shigaki, I. S., \& Smith, S. A. (1997). A cultural sharing model: American buddies for international students. International Education, 27, 5-21.

Snow, D. (2006). More than a native speaker: An introduction for volunteers teaching abroad. Alexandria, VA: TESOL.

Sundstrom, C. J. (2009). Graduate support program: The least we owe international graduate students. In M. S. Andrade \& N. W. Evans (Eds.), International students: Strengthening a critical resource (pp. 157-162). Washington, DC: ACE/Rowman Littlefield.

Swain, M. (1995). Three functions of output in second language learning. In G. Cook, \& B. Seidlhofer (Eds.), For H.G. Widdowson: Principles and practice in the study of language (pp. 125-144). Oxford, UK: Oxford University Press.

Trice, A. G. (2003). Faculty perceptions of graduate international students: The benefits and challenges. Journal of Studies in International Education, 7(4), 379-403.

Wu, S., Griffiths, S., Wisker, G., Waller, S., \& Illes, K. (2001). The learning experience of postgraduate students: Matching methods to aims. Innovations in Education and Teaching International, 38(3), 292-308. 